\title{
ON THE MECHANISM \\ OF INTERPRETING ENGLISH TENSES IN INDIRECT SPEECH COMPLEMENT CLAUSES
}

\author{
NAOAKI WADA \\ Ibaraki University
}

\begin{abstract}
This paper provides a principled explanation of the mechanism of interpreting English tenses in indirect speech complement clauses. To this end, the paper proposes an interpretive principle which is based on two theories: a compositional tense theory and Hirose's (1995, 1997a, 1997b) theory of reported speech. The former theory requires a distinction between the level of tense structure and the level of tense interpretation, on one hand, and a distinction between the absolute and the relative tense component, on the other; the latter theory introduces the notions of public self and private self. It will be shown that the proposed principle can not only solve problems with previous analyses, but also account for a variety of related temporal phenomena in English indirect speech.*
\end{abstract}

\section{Introduction}

The mechanism of interpreting English tenses in indirect speech complement clauses (CCs), widely known as the sequence of tenses phenomenon, has been analyzed by many grammarians and linguists. Among previous studies on this phenomenon, two types of analyses have been prevalent: the "sequence-of-tenses rule" analysis (e.g. Comrie (1986), Costa (1972), Coulmas (1986), and Hornstein (1990)) and the "relative time" analysis (e.g. Dahl (1987), Declerck (1991b, 1995), Smith (1978, 1981b), and Wekker (1980)). However, they all have either some theoretical or empirical problems, or both. Some of them do not give a systematic explanation for the phenomenon; others pay little attention to the nature of indirect speech, thus failing to illu-

* I would like to express my deepest gratitude to Yukio Hirose and Masao Okazaki for giving me invaluable comments and suggestions on earlier versions of this paper. I also thank the following people: Yuichi Mori for fruitful discussions; two anonymous $E L$ reviewers for their insightful comments; Joyce Cunningham, Linda Ghan, and Nina Padden for answering my questions about English data and improving my English. All remaining inadequacies are, of course, my own. 
minate the mechanism of the phenomenon.

The present paper aims to provide a principled explanation of how to interpret English tenses, especially past tenses, in indirect speech CCs. To this end, I propose an analysis consisting of two theories: a compositional tense theory and Hirose's $(1995,1997 \mathrm{a}, 1997 \mathrm{~b})$ theory of reported speech. The compositional tense theory requires a distinction between the levels of tense structure and tense interpretation, on one hand, and a distinction between the absolute and the relative tense component, on the other. The reported-speech theory presents the notions of "public self" and "private self" which presuppose the notions of "public expression" and "private expression." It will be demonstrated that our analysis based on the two theories can not only solve the problems with the previous analyses, but explain a variety of related phenomena in indirect speech from a unified point of view.

\section{Previous Analyses}

\subsection{The Sequence-of-Tenses Rule Analysis}

The proponents of the sequence-of-tenses rule analysis state a formal rule in the following manner: when a direct speech sentence is changed into an indirect speech counterpart, the tense of the original utterance in the reported clause must be backshifted if the verb in the reporting clause is in the past tense, while the tense of the original utterance in the reported clause must be retained if the verb in the reporting clause is in the non-past tense. ${ }^{1}$

This analysis, however, raises some problems. Let us examine just two of them for lack of space (see Declerck (1991b) for details) $:^{2}$

1 This kind of analysis needs an additional semantic account to explain the case where in indirect speech the $\mathrm{CC}$ tense is present while the matrix clause tense is past (cf. Comrie (1986) and Costa (1972)). For further discussion and criticism of the analysis, see Tanaka (1991). It is shown in section 4.1 that our analysis can explain this fact from a unified point of view.

2 One might say that Hornstein's (1990) sequence-of-tenses analysis can deal with the temporal interpretations in (1) and (2). He assumes two rules: a sequence-oftenses rule which links the $\mathrm{CC}$ time with the matrix clause (MC) time and a default rule which links the $\mathrm{CC}$ time with the speech time $(\mathrm{S})$. Thus, it virtually bears the same result as the relative time analysis (see note 6). However, he does not answer the fundamental question of why the morphological change of the CC tense is brought about when the MC tense is past, whereas it is not when the MC tense is 
(1) a. They will report tomorrow that Harry is transmitting.

b. They will report tomorrow: "Harry was transmitting (yesterday)."

(2) a. Mary said, "Nancy had gone to Italy."

b. Mary said that Nancy had gone to Italy.

In (1a), the CC situation can be viewed as referring to present time. ${ }^{3}$ In this case, (1a) can be seen as an indirect speech version of (1b), so that the formal rule cannot account for why the tense of the original utterance (i.e. the past tense) in (1b) is changed into the present tense in (1a); for the rule wrongly predicts that the tense of the original utterance in (1b) should be retained. Moreover, the formal rule cannot explain why in (2b), when interpreted as an indirect speech version of (2a), the pluperfect is not backshifted. If the sequence-of-tenses phenomenon were caused by the formal rule at issue, backshifting a pluperfect would theoretically be possible. However, this is not the case. $^{4}$

\subsection{The Relative Time Analysis}

Let us now turn to the relative time analysis, where the $\mathrm{CC}$ time can be related to the matrix clause (MC) time semantically. Previous studies of this type also pose problems. Most of the studies deal only with a limited number of data, not providing a systematic or principled explanation for the sequence-of-tenses phenomenon.

Smith $(1978,1981 b)$ analyzes the phenomenon in terms of two interpretive principles, i.e. the "sharing" and "orientation" principles, and a performative analysis. With the sharing principle, the MC time functions as the reference time of the $\mathrm{CC}$; this is exemplified in a sentence like The nurse explained that the doctor was busy. With the orienta-

non-past. Moreover, he cannot explain why in a sentence like Bruce said that Mary was pregnant (see (3) in the text), the CC time cannot be viewed as posterior to the MC time; for when a default rule is operative, it should be logically possible that it is so. Thèse points are discussed in detail in section 3. See Mihara (1992: 132-134) for further criticism of Hornstein's analysis.

3 In this paper, the term situation stands for any kind of eventuality described by a predicate.

4 One might say that the impossibility of backshifting the pluperfect is due to the lack of having a tense expressing further anteriority to the pluperfect in English. The question, then, arises of why it is so (cf. Declerck (1991b: 178)). A convincing answer will be given in this paper. 
tion principle, the MC time serves as a time of orientation from which the CC time is computed; this is exemplified in a sentence like The report states that the spy was denounced last month. When the two principles are not effective, a performative analysis is operative: in the interpretation of a sentence like Rieko said that Natsumi is happy, the CC tense is interpreted in relation to the tense in an abstract performative clause. However, she does not clarify why the principles can work in indirect speech nor does she make clear the relation between the two principles. $^{5}$ (For other problems with her analysis, see Binnick (1991: 352-353).) It will be shown in section 3 that my analysis requires only one motivated principle.

Declerck (1991b, 1995) presents one of the most effective explanations for the phenomenon at issue. However, his analysis also causes some problems. The first problem, which is common to other relative time analyses, is that his analysis as it stands cannot explain why sentences like those in (3) and (4) cannot receive what I call the posterior reading, where the $\mathrm{CC}$ time is interpreted as coming after the $\mathrm{MC}$ time.

(3) a. Mary said that she was pregnant.

b. I heard that Sally was in London.

(4) a. Mary said that she finished her homework.

b. John said that he wrote a book.

The sentences in (3) are temporally ambiguous in two ways (cf. Enç (1987: 635)). One reading is the anterior reading, where the CC time is viewed as coming before the MC time. The other is the simultaneous reading, where the $\mathrm{CC}$ time is seen as coinciding with the $\mathrm{MC}$ time. On the other hand, the sentences in (4) receive only the anterior reading because of the bounded nature of the $\mathrm{CC}$ situations: i.e., in order for a bounded situation to be true at the MC time, its end-

5 It is stated in Smith (1978) that the sharing principle works when the MC tense is the same as the $\mathrm{CC}$ tense, and the orientation principle works when the MC tense is different from the $\mathrm{CC}$ tense. However, she herself obscures the relation between the sharing and the orientation principle by applying the latter to a sentence in which the MC tense is the same as the CC tense (see especially Smith (1981b: 224)). What is worse, she finally reaches the conclusion that the two principles work only when the MC tense is the same as the $\mathrm{CC}$ tense, and two more special principles are necessary when the MC tense is different from the CC tense (see Smith (1981b: 226)). 
point must be reached before that time.

Whether or not the simultaneous reading is possible does not matter here (this will be discussed in section 3.5). The point is that the CC time is never seen as coming after the MC time. Declerck considers that the CC tense can be either absolute or relative. Thus, it should be theoretically possible for (3) and (4) to receive the posterior reading. This is because in the use of absolute past tenses in CCs, what is relevant is the temporal relation between the speech time (S) and the $\mathrm{CC}$ time, not that between the MC and CC times. This implies that in his system, CC times can come after MC times insofar as they are in the past. Indeed he argues that in the case of the posterior reading, the $\mathrm{CC}$ verb must be in the predictive form (i.e. would +infinitive), but he still does not answer the fundamental questions: why (3) and (4) cannot allow the posterior reading of absolute past tenses in CCs and why the predictive form should be used when we refer to a future-inthe-past situation (these points will be clarified in section 3).

Still another problem is that his analysis in terms of "temporal domain," i.e. a set of one time or more, cannot explain the ungrammaticality of (5).

(5) a. *Rieko said that she would leave when I arrived tomorrow.

b. *John expected that he would be there when I arrived tomorrow.

He claims that in a past (temporal) domain whose central situation is represented by the MC verb in the absolute past tense expressing anteriority relative to $S$, the relative (simple) past tense represents simultaneity, the pluperfect anteriority, and the conditional or the future-inthe-past tense posteriority. Thus in (3a), the absolute past tense said establishes a past domain, representing the MC time as a base time for the calculation of subordinate tenses, and the relative past tense was expresses simultaneity relative to the $\mathrm{MC}$ time as the base time. $\mathrm{He}$ also claims that the semantic structure of when is equivalent to at the time at which (cf. Declerck (1996)). Thus, the sentence I loved her when I was young is equivalent to I loved her at the time at which I was young.

The criticism proceeds in the following way. First, as (6) shows, the conditional tense can refer to future time relative to $\mathrm{S}$.

(6) a. Rieko said that she would leave tomorrow.

b. John expected that he would be there tomorrow. 
What is important is that in (6a), for example, the CC tense associated with would leave represents posteriority in the past domain established by the MC verb, i.e. said, and the time of Rieko's leaving, even if referring to the future, can be incorporated into that past domain. This implies that the same applies to the predicate would leave in (5a). Secondly, in (5) the semantic structure of the relative past tense in the when-clause (WC), i.e. arrived, is assumed to represent simultaneity with respect to the implicit time indicated in when, i.e. the time in its paraphrase mentioned above, which is in turn simultaneous with the time of Rieko's leaving because of the lexical property of the first at in the same paraphrase. Thus, it should be the case that in his system, all the times in (5) hold true in the past domain established by the MC verb. As a result, his analysis predicts that in syntactic environments like those in (5), the relative past tense in the WC should go with future-time adverbials, and, thus, (5) should be grammatical; but this is not the case. ${ }^{6}$

To summarize this section, none of the previous analyses have succeeded in explaining tense phenomena appropriately in indirect speech CCs. This might be partly due to the fact that they have paid little attention to the nature of indirect speech complements with respect to interpretation of tenses in CCs, or partly because they mix the semantic structure of a tense form per se with the interpretation of a tense form. To the best of my knowledge, it is Hirose (1995, 1997a, 1997b) who provides a principled explanation of the nature of indirect speech phenomena including tense phenomena. However, he does not deal with the behavior of tense in detail; in addition, he does not explain why his principle about tenses in indirect speech (presented in section 3.2 below) should be as it is.

Taking these observations into account, in the next section I will first propose a compositional tense theory which distinguishes the level of tense structure and that of tense interpretation, and then develop Hirose's analysis a little more fully in terms of the proposed tense

6 In fairness to Declerck, I have to say that his system (and perhaps other relative time analyses) can explain the tense phenomena in (1) and (2). In (1a), since the $\mathrm{CC}$ situation is interpreted in relation to $\mathrm{S}$, the present progressive, an absolute tense form, is chosen which refers to a specific ongoing situation holding true at $S$. In the relevant reading of $(2 b)$, the reason why the pluperfect is not backshifted is that even in this case, the pluperfect still expresses anteriority in the past domain. 
theory. It will be shown that our new analysis provides a more principled and motivated explanation not only for the phenomena that the previous analyses cannot account for, but also for further related tense phenomena in English indirect speech CCs.

\section{An Alternative Analysis}

\subsection{A Compositional Tense Theory}

This subsection presents a compositional tense theory which consists of the levels of tense structure and tense interpretation. At the level of tense structure, the semantic structure of a tense form per se represents its original temporal value. At the level of tense interpretation, elements other than tense structure such as time adverbials, contexts, and syntactic environments contribute to determining the temporal value of a tense form; the original value of a tense form shows up by default, changes into another value or is fixed at a certain value.

\subsubsection{Tense Structure}

Let us start by examining the level of tense structure. This tense theory presupposes the traditional distinction between finite and nonfinite forms (cf. Nakau (1994: Ch.14)). A sentence always requires at least one finite predicate; whenever a nonfinite predicate exists in a sentence, a finite predicate necessarily does.

With this in mind, I will offer the following hypothesis with respect to English tense structure:

(7) In English, a finite predicate consists of both the absolute tense component (henceforth the A-component) and the relative tense component (henceforth the R-component), whereas a nonfinite predicate consists only of the R-component. ${ }^{7}$

The A-component is represented by a tense morpheme establishing either the past or present (or non-past) time-sphere. ${ }^{8}$ This component is absolute because the establishment of a time-sphere is based on a direct relation to the speaker's point of view, which adheres to $S$,

7 It is shown in Wada (1995) that the dual-component tense theory is also useful in elucidating the nature of the English perfect.

8 The concept of time-sphere is semantically almost equivalent to Declerck's "time-sphere." However, he does not directly connect it with a morphological element, i.e. a tense morpheme, let alone with a compositional tense theory. 
i.e. the absolute time point on the time line. The R-component is represented by the time of an event (or a situation). This component is relative in the sense that the position of the event time is not tensestructurally determined in a direct relation to $\mathrm{S}$.

In English, a finite predicate is seen as an absolute tense form because it contains the A-component; a nonfinite predicate, by contrast, is viewed as a relative tense form in that it does not contain the A-component, but contains only the R-component. With a finite predicate, the temporal relation of the A-component to the R-component is always that of inclusion in the sense that the event time associated with the R-component always obtains somewhere (or is always included) in a time-sphere associated with the A-component.

With a nonfinite predicate, on the other hand, the position of its event time is determined with respect to another (event) time as a base time. In this case, three types of relations are possible: anteriority, simultaneity and posteriority. We assume that English has five nonfinite tense forms, i.e. the present and past participles, the to- and bare infinitives, and the gerund; each nonfinite form expresses one or two of the three temporal relations.

To illustrate these points, let us consider (8):

( 8 ) a. I lived in Tsukuba.

b. Sitting here in the sun, I still feel cold.

c. I remember traveling to Italy with her.

In (8a), because the verb lived is a finite predicate, it has both the Aand the R-component. The A-component establishes the past timesphere and the R-component locates the event time somewhere in that time-sphere. This is all the past tense at issue says at the tense-structure level. The nonfinite predicates in $(8 b, c)$, by contrast, have only the R-component. In (8b), sitting has only the R-component, representing simultaneity, because the nature of the present participle is to describe an ongoing situation. Which time the event time of sitting is simultaneous with is not clarified at this level. In (8c), traveling to Italy expresses non-posteriority, i.e. simultaneity or anteriority, because the nature of the gerund is to express an experience (one can experience something only when it holds true now or in the past). Which temporal relationship the predicate at issue expresses is not determined at this level. It is the level of tense interpretation that we can finally determine the temporal values of these nonfinite predicates. 


\subsubsection{Tense Interpretation}

Let us now move to the level of tense interpretation. At this level, two kinds of interpretations are possible: deictic and non-deictic interpretation. In the former interpretation, the event time of a finite predicate is interpreted in a direct relation to $\mathrm{S}$, while in the latter, it is interpreted in relation to another event time as a base time.

Let us first consider the following finite predicates:

(9) a. If you come with me, you will enjoy the party.

b. One day, Naomi said to Oscar that she saw him the day before.

(Comrie (1986:273))

In (9a), at the level of tense structure, the finite verb come itself does no more than convey that its tense morpheme establishes the present time-sphere and its event time is located somewhere in that timesphere. Only at the level of tense interpretation can the event time be interpreted as simultaneous with (more precisely, coming just before) the main-clause time (i.e. the time of the addressee's enjoying) by virtue of the nature of normal conditional clauses. The point here is that come, which is an absolute tense form, receives the non-deictic interpretation. A similar observation applies to (9b). At the tense-structure level, both said and saw only establish the past time-sphere, representing their event times somewhere in that time-sphere. The temporal relation between the two situations is vague at this level. It is at the level of tense interpretation that the relation between the event times under consideration is determined. Since the event time of the $\mathrm{MC}$ verb is normally interpreted in relation to $\mathrm{S}$, the event time of said is viewed as coming before $\mathrm{S}$. That is, said receives a deictic interpretation. The event time of saw, by contrast, is construed as coming before the event time of said as a base time because of the lexical property of the relative time adverb the day before. Thus saw is interpreted non-deictically.

I now move to nonfinite predicates. Consider $(8 \mathrm{~b}, \mathrm{c})$ again. It is at the level of tense interpretation that the temporal relations of the nonfinite times to other times are finally determined. In (8b), the event time of sitting is interpreted as coinciding with that of the finite predicate $f e e l$ at this level. The same applies to (8c). Only at this level can we fix the temporal value of the gerund traveling to Italy; we can interpret its event time as coming before that of the finite verb remember because of the interaction between the nature of the gerund and the lexical property of the finite verb. 
To sum up, by assuming the levels of tense structure and tense interpretation, we can give a motivated answer to the question of why predicates in the same tense can be interpreted ambiguously (e.g. said and saw in (9b)) (I will discuss this point in detail in section 3.6). Moreover, we can avoid ascribing too much to the semantics of a tense form; I argue that at the tense-interpretation level, the information conveyed by a tense form per se interacts with the information associated with elements other than tense structure in order for the tense form to receive an appropriate interpretation. ${ }^{9}$

\subsection{Hirose's Theory of Reported Speech}

One aim of Hirose's theory of reported speech is to provide a principled explanation for syntactic and semantic differences between Japanese and English indirect speech. Above all, how to explain tense behavior in indirect speech within his framework is directly relevant to

9 The proposed tense theory can also be applied to the Japanese tense system. I assume that the tense structure of Japanese predicates consists only of the R-component; basically, the $t a$-form represents anteriority, a stative predicate in the $r u$-form simultaneity, and a non-stative predicate in the $r u$-form posteriority. Like English finite predicates, however, Japanese predicates can also receive either a deictic or non-deictic interpretation at the tense-interpretation level. Observe (i):

$\begin{aligned} \text { (i) a. } & \text { Mana-wa kino koto-o hiita. } \\ & \text { Mana-Top yesterday koto-Acc play-Past } \\ & \text { Mana played the koto yesterday.' } \\ \text { b. } & \text { Kanojo-ga asu goji-ni shuppatsushita-atode, boku-wa } \\ & \text { she-Nom tomorrow five-at leave-Past after I-Top } \\ & \text { kokyo-e kaeru } \quad \text { (tsumorida). } \\ & \text { hometown-to return-Pres }\end{aligned}$

'After she leaves at five tomorrow, I will return to my hometown.'

Acc stands for accusative case marker, Nom for nominative case marker, and Top for topic marker. In (ia), the tense structure of hiita 'played' expresses anteriority. At the tense-interpretation level, the absolute time adverb kino 'yesterday' causes it to refer to past time relative to $\mathrm{S}$. Thus hiita receives a deictic interpretation. In (ib), at the tense-structure level, kaeru 'return' (i.e. a non-stative predicate in the $r u$-form) expresses posteriority and shuppatsushita 'left' (i.e. a ta-form) expresses anteriority. At the tense-interpretation level, the event time of kaeru is construed as posterior to $\mathrm{S}$ because a main-clause predicate has a strong tendency to be connected directly with $\mathrm{S}$; the event time of shuppatsushita is interpreted as anterior to the event time of kaeru because temporal clauses are usually subordinate to main clauses syntactically and semantically. Thus, kaeru receives a deictic interpretation while shuppatsushita receives a non-deictic one. The point here is that in our system, although Japanese predicates lack the A-component, they can receive deictic interpretations. 
the present discussion. Thus, I restrict myself to the tense behavior. Hirose (1997a: 33) offers the following principle:

(10) The use of tenses in the indirect speech CC is attributed to the private self in Japanese, while it is attributed to the public self in English.

Before examining how this principle works, we have to see the background to understand this principle. First of all, as a basis for his explanation, Hirose (1995: 226) proposes the following hypothesis:

(11) Direct speech is a quotation of 'public expression' and indirect speech is a quotation of 'private expression.'

He defines "public expression" as the level of linguistic expression corresponding to the communicative function of language, and "private expression" as the level of linguistic expression corresponding to the non-communicative or thought-expressing function of language. The hypothesis in (11) thus means that while direct quotes can report communicative attitudes of the original speaker, indirect quotes correspond to mental-state representations or subjective thoughts of the original speaker. It should be noted here that the communication of thoughts presupposes the expression of thoughts. This means that public expression consists of private expression and communicative attitudes (or addressee-orientedness).

To illustrate this point, consider (12):

(12) a. Rieko said, "Natsumi is sick."

b. Rieko said that Natsumi was sick.

In (12a), by using the direct quote the reporter reports the communicative attitudes of the original speaker, i.e. Rieko. In other words, the reporter reports Rieko's original utterance, i.e. her public expression. In (12b), by contrast, by using the indirect quote the reporter represents only the mental state or thought of the original speaker, i.e. Rieko's private expression.

Let us now consider the concepts of "public self" and "private self," which play an important role in the principle in (10). Public self is defined as the subject of public expression, i.e. the subject of a communicating act, and private self as the subject of private expression, i.e. the subject of a thought-expressing act. Public self and private self are two different aspects of the same speaker. Thus in $(12 a, b)$, the reporter is, by definition, depicted as public self, because he or she is communicating the content of the sentence to the addressee. By contrast, in (12a), the original speaker (i.e. Rieko) is depicted as public 
self by the reporter because the reporter is reporting her original utterance including her communicative attitudes; in (12b), Rieko is depicted as private self in that the reporter is reporting her original thought without her communicative attitudes. ${ }^{10}$

There is good evidence to prove that in indirect speech, the subject of a whole sentence is represented as a private self. Mental-attitude adverbials like probably and possibly are used to express a mental attitude of an original speaker toward a given proposition in the indirect quote (cf. Hirose (1995: 234)). Consider (13):

(13) a. John says that the news is probably true.

b. John thinks that Mary may possibly be a spy.

In (13a), for example, probably represents the mental attitude of the original speaker (i.e. John) toward the proposition of the news being true. Since a private self is the subject of a mental-state expressing act, John is depicted as a private self. The same applies to Japanese data (see Hirose (1995: 232-233)).

Having seen the background, we can now examine how the principle in (10) works. Observe (14):

(14) a. Mary said (that) Nancy was pregnant.

b. Mary-wa Nancy-ga ninshin shiteiru to itta. Mary-Top Nancy-Nom pregnant be-Pres Quot say-Past 'Mary said that Nancy was pregnant.'

In (14b), Top, Nom and Quot stand for topic marker, nominative case marker and quotative particle, respectively. Both sentences are represented schematically as follows:

(15) a. [Mary said $\langle$ Nancy [was] pregnant $\rangle]$

b. [Mary wa $\langle$ Nancy ga ninshin shiteiru $\rangle$ to itta]

The square brackets represent public expression and the angle brackets

10 One might claim that Bruce in (i) might be a public self, saying that Bruce is the subject of communicating the content of the CC to John.

(i ) Bruce said to/told John that Mary was pregnant.

As is shown in the text, however, the reporter's use of the indirect quote indicates that the CC does not represent Bruce's original utterance, but rather represents his private expression or what he intends to convey; it no longer reflects Bruce's original utterance including his communicative attitude. This is verified by the fact that in a sentence like Bruce said (to John) that frankly, Mary was lying, the communicative-attitude adverb frankly cannot express a communicative attitude of the original speaker, i.e. Bruce, but it expresses the reporter's one. Hence, Bruce is depicted as a private self. 
private expression. In $(14 a, b)$, the reporting clauses are the reporter's public expressions. With the CCs, English behaves differently from Japanese. ${ }^{11}$ In the Japanese version (14b), all the elements in the CC are attributed to the private self because they constitute private expression. In the English version (14a), by contrast, the preterite was in the $\mathrm{CC}$ is attributed to the reporter as public self. To put it another way, the pastness represented by was is determined by the reporter's responsibility.

This fact is compatible with the nature of indirect speech complements; in indirect speech, the reporter is free to blend some information from the reporter's own point of view with the original speaker's mental state insofar as the reporter preserves what the original speaker intends to convey (cf. Coulmas (1986:2-3)). It is thus possible that in English, as far as tenses are concerned, the reporter as public self superimposes his or her public expression on the original speaker's private expression. In (14a), for example, underlying the reporter's public expression was is the original speaker's private expression am.

\subsection{Justification and Extension}

We can now justify and extend Hirose's principle in (10). First, let us consider why the use of tenses must be attributed to the public self in English indirect speech CCs. The tense theory proposed in section 3.1 can answer this question. As we have seen, the proposed tense theory requires that an English finite predicate have the A-component which establishes a time-sphere. In (14a), for example, the A-component of was pregnant represents the past time-sphere which is past relative to $\mathrm{S}$, to which the reporter as public self pertains. This means

11 Hirose's main concern is to explain why Japanese pronouns behave differently from English ones in indirect speech, though I ignore reference to pronouns because they are not directly relevant to the present discussion. A short sketch of his explanation of Japanese and English pronouns is as follows. Hirose (1997a: 11-13) notes that Japanese has a special word for private self, i.e. jibun, and a number of words (e.g. boku 'I' and kimi 'you') are used to represent public self, depending on who is talking to whom. By contrast, Hirose (1997a: 16) states that English does not have any special word for private self, but has words for public self such as $I$, you and she; thus, "in English, personal pronouns, which are primarily defined as public expressions, are diverted to represent the private self, depending on whether the subject of the private expression in question is the first, second, or third person (Hirose (1997b: 7)." See Hirose (1995, 1997a, 1997b) for details. 
that in indirect speech, using English absolute tense forms, i.e. finite predicates, amounts to reflecting the point of view of the reporter as public self. We can thus say that the statement with respect to English tenses in Hirose's principle comes necessarily from the tense structure of English finite predicates. ${ }^{12}$

Let us now turn to an extension of the principle in (10). In order to explain why sentences like those in (3) and (4) allow no posterior reading, clarifying the role of modality in indirect speech CCs is necessary. In this paper, modality is defined as a speaker's subjective attitude toward a proposition. A speaker can be depicted as either a public or a private self.

Moreover, distinguishing the viewpoint of a public self from his or her consciousness is also inevitable because in some cases, the viewpoint of the public self is separated from the consciousness of the public self (I will discuss this in section 4.4). Consciousness is defined as the mind of an individual doing any kind of mental activities. On the other hand, a viewpoint is defined as an evaluation pivot from which one evaluates or calculates something linguistic or non-linguistic. As far as time reference is concerned, a viewpoint corresponds to a time of orientation, i.e. a base time from which a given event time is computed. However, we can also use a viewpoint as an evaluation pivot in, say, determining which pronoun we should choose. A viewpoint is thus a broader notion than a time of orientation. Through the viewpoint, a speaker's consciousness can have access to the outer world (note that usually, a speaker's consciousness and viewpoint coexist).

Taking these matters into account, I will offer a principle like the one in (16), which consists of both an extended version of the statement as to English tenses in (10) and a generalization about English modal elements.

12 The proposed tense theory can also provide a more principled explanation for why in (10), the use of Japanese tenses in indirect speech CCs is attributed to the private self. Thus in (14b), as we have seen in note 9, ninshin shiteiru 'being pregnant' has only the R-component. This implies that its temporal interpretation does not necessarily depend on the point of view of the public self, but it can depend on the point of view of some other person. Since the CC is subordinate to the MC, the event time of ninshin shiteiru in the $\mathrm{CC}$ can be computed from the point of view of the private self. 
(16) In English indirect speech CCs, the R-component of a finite predicate can be connected with the viewpoint of the public self either directly or via the viewpoint of the private self; modal elements must be attributed to the private self. ${ }^{13}$

This principle provides an explanatory basis for interpreting the mechanism of English indirect speech CCs, working at the level of tense interpretation.

Let us first examine the above statement pertaining to the relation between modal elements and private self. It suggests that as with modal adverbials like probably in (13), modality-related notions like assertion, prediction and uncertainty are private expressions, i.e. subjective thoughts of the private self, in that the modality-related notions also express the speaker's subjective attitudes (cf. also Yukio Hirose (personal communication)). Thus, modality cannot freely be changed by the reporter as public self. Consider (17):

(17) a. Mana said that she won the fourth prize in the koto contest.

b. Rieko said that she would move to another office.

In (17a) the CC verb won is in the assertive form and in (17b) the CC verb would move is in the predictive form. Since the assertion and the prediction involved are ascribed to Mana and Rieko respectively, the reporter cannot replace them with other modalities without a change of meaning.

Let us now consider the above statement with respect to the relationship between viewpoints and the R-component (associated with the event time) of a finite predicate. It suggests that the public self can attribute the interpretation of the event time of the $\mathrm{CC}$ predicate, either directly or via the viewpoint of the private self, to the viewpoint of the public self. This is highly motivated in the sense that since there are two viewpoints of speakers (i.e. the viewpoints of a reporter and an original speaker) in indirect speech, a CC situation has the potential to be related to either of the two viewpoints.

Observe the following:

13 Mihara (1992: 43-44) claims that in indirect speech, the viewpoint is fixed on S, citing a sentence like (35b) from Smith (1978). As is discussed in section 4.2, however, this does not necessarily adduce evidence for his claim. What is worse, Mihara's claim cannot explain why (23) is ungrammatical. 
(18) Bruce said that Mary was pregnant.

(19) Rieko said that Natsumi celebrated her birthday three days ago.

(20) One day, Naomi said to Oscar that she saw him the day before. $(=(9 b))$

In (18), the preterite in the CC can receive either a deictic or non-deictic interpretation. The A-component of was pregnant establishes the past time-sphere; the time of the situation of Mary's being pregnant, which constitutes the R-component of was pregnant, can be connected with the reporter's viewpoint, either directly or via Bruce's viewpoint. This ambiguity is disambiguated by the co-occurrence with temporal adverbials, as exemplified in (19) and (20). In (19) the deictic time adverb three days ago causes the deictic interpretation of celebrated, while in (20) the non-deictic time adverb the day before causes the nondeictic interpretation of $s a w .^{14}$

\subsection{Explanation}

We are now in a position to solve the problems with the previous analyses. I begin with Declerck's first (and other relative time analyses') problem, namely, why the simple past tense in CCs is not allowed to receive the posterior reading. From (16), it follows that modality in the $\mathrm{CC}$ is attributed to the private self. In order to assert something, normally it is already known at the time when the assertion is made. In other words, we can usually make an assertion only about a situation which coincides with, or is prior to, the time of assertion. Given this, it follows that the private self can make an assertion about the $\mathrm{CC}$ situation only when the CC time coincides with, or comes before, the MC time. Since the CC predicates in (21) and (22) are in the assertive form, both sentences do not allow the posterior reading.

(21) Mary said that she was pregnant. $\quad(=(3 a))$

(22) Mary said that she finished her homework. $\quad(=(4 a))$

Principle (16) can also account for the ungrammaticality of (23), where the time adverbs make it clear that the CC times come after the

14 Smith (1981b: 219) notes that some native speakers interpret a deictic adverb like three days ago in such a way that its base time is the MC time. In this case, we can say that such speakers take the non-deictic interpretation of the event time of the CC predicate. Thus, the fact does not undermine, but rather supports, my theory. 
MC times. ${ }^{15}$

(23) a. *Two days ago Betty said that she threw a party last night.

(Declerck (1991b: 183))

b. ${ }^{*}$ In 1970 , Graham said that he got tenure in 1980 .

(Comrie (1986: 281))

When referring to a situation which is future relative to a base time, we usually cannot make an assertion about that situation, but rather predicts it. In (23), on the other hand, the assertive forms are used to refer to the situations in the future relative to the MC times as the base times. Such a contradiction makes (23) ungrammatical.

Let us now move to the solution to Declerck's second problem, i.e., why sentences like those in (5) are ungrammatical.

(5) a. * Rieko said that she would leave when I arrived tomorrow.

b. *John expected that he would be there when I arrived tomorrow.

Take (5a) for example. In the proposed theory, the finite predicate arrived in the $\mathrm{WC}$ has the A-component establishing the past timesphere, so that the time of arriving must happen in the past. Thus the co-occurrence of arrived with the future time adverb tomorrow results in a contradiction. Hence the ungrammaticality of (5a).

It is worth noting here that our analysis can also account for the grammaticality of (6).

(6) a. Rieko said that she would leave tomorrow.

b. John expected that he would be there tomorrow.

Take (6a) as an example. Since the nonfinite predicate leave itself does not have the A-component, its event time does not necessarily happen in the past time-sphere. At the tense-structure level, the infinitive leave merely expresses a situation not yet realized. At the tense-interpretation level, because of the property of the form of will+ infinitive, the nonfinite predicate in question can represent posteriority relative to the time of a prediction associated with would (see Wada (1996) for details). It is thus possible that the event time of leave is interpreted as occurring in the future relative to $\mathrm{S}$; the verb leave can go

15 Declerck (1991b: 160) claims that the use of the absolute (past) tense is allowed "only if the temporal order of the situations is clear from a temporal adverb, the context or from the hearer's pragmatic knowledge of the world." However, this kind of account is falsified by the ungrammaticality of (23). 
with the future time adverbial tomorrow.

Note that our analysis can, from a unified point of view, solve the problems with the sequence-of-tenses rule analysis, which are exemplified in (1a) and (2b), repeated as $(24 a, b)$.

(24) a. They will report tomorrow that Harry is transmitting.

b. Mary said that Nancy had gone to Italy.

In (24a), at the tense-structure level, both will and is transmitting establish the present time-sphere in which their event times are located. At the tense-interpretation level, the event time of is transmitting is connected with $\mathrm{S}$, but not the time of reporting, because of the context. Let us now turn to (24b). In our analysis, whether the reference time of had gone is simultaneous with, or comes before, the time of said is irrelevant when we use the pluperfect; for at the tense-structure level, the pluperfect itself establishes the past time-sphere and represents its event time as coming before its reference time in that time-sphere. At the tense-interpretation level, which interpretation we choose is determined by the context.

\subsection{Two Readings of Unbounded Sentences and Temporal Focus}

It remains an unsettled question how to distinguish the simultaneous from the anterior reading of unbounded CCs like those in (3). First, observe (3a) again, which is repeated here as (25):

(25) Mary said that she was pregnant.

As has been mentioned in section 2.2, a sentence like (25) allows the two readings: the anterior and the simultaneous reading. This is due to the interaction between the homogeneous nature of the unbounded clause in the $\mathrm{CC}$ and the nature of the assertive form was; i.e., although the homogeneity of was pregnant makes it possible that the $\mathrm{CC}$ situation holds true throughout the past time-sphere, the nature of assertion ascribed to the private self (i.e. Mary) causes the situation at issue to hold true only in the period which starts before, and leads up to, the time of Mary's utterance.

We can now consider how to distinguish the anterior from the simultaneous reading. To this end, I will make use of Declerck's concept of "temporal focus" with a slight change of definition (for a detailed discussion on the usefulness of temporal focus, see Wada $(1995,1996))$ :

(26) Temporal focus (TF) is a speaker's focus, which is fixed on the time point (or period) to which the speaker is paying attention. 
In the case of indirect speech, we regard a speaker in (26) as corresponding to the reporter as public self. Given this, we can say that whether sentence (25) receives the simultaneous or the anterior reading depends on which part of the situation the public self directs the TF at. Both readings are schematized below:

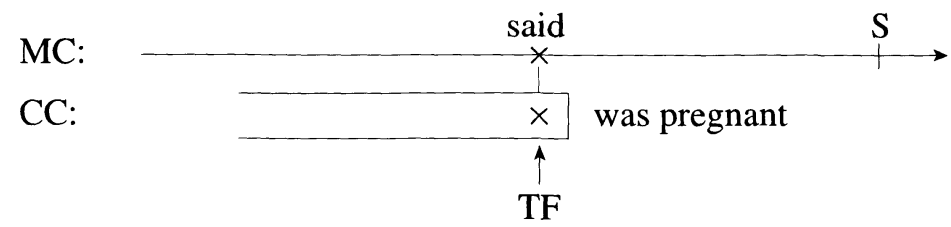

(28)

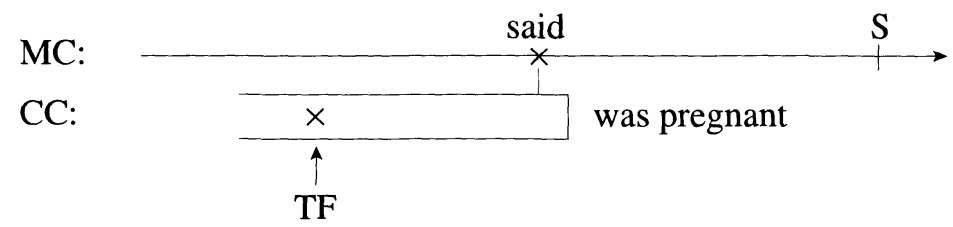

(27) represents the simultaneous reading and (28) the anterior one. Time flows from left to right. A cross denotes the position of an event time and a rectangle with its left open symbolizes the zone where the private self's assertion holds true. It is clear from the above schemata that both readings are distinguished from each other by means of the difference of the position of the TF. This distinction is done at the tense-interpretation level.

\subsection{Homophonous vs. Polysemous}

Before concluding this section, I will touch on the question of whether English past tenses represent a homophonous or polysemous relationship. In my theory, as with past tenses in independent clauses and MCs, past tenses in CCs have the A-component. There is, however, one difference between the former and the latter type of past tenses. The former type is usually interpreted deictically. This is the default case. As we have seen, by contrast, past tenses in CCs can be interpreted either deictically or non-deictically because of the presence of the two viewpoints, i.e. those of the public self and the private self. Taking the discussion thus far into consideration, the two possible deictic and non-deictic interpretations of the past tense can be schematized in (29) and (30). 
(29)

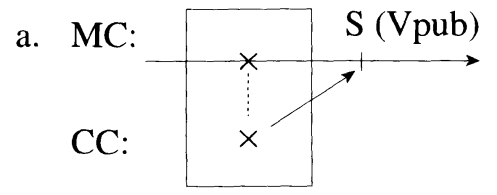

(30)

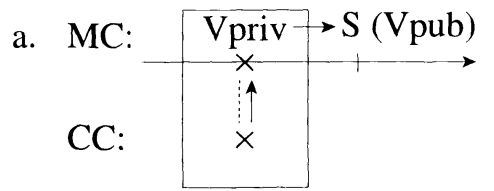

b. MC:

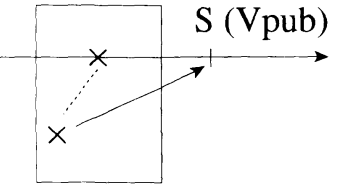

b. MC:

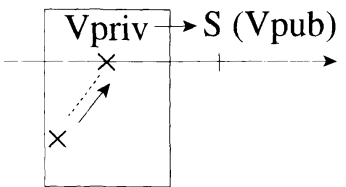

Vpub and Vpriv symbolize the viewpoints of the public self and the private self, respectively. The box represents the past time-sphere and the cross the position of the event time. An arrow represents a mental path reaching a viewpoint and a broken line the temporal relation between the MC and CC times. Both diagrams in (29a) and (30a) indicate the simultaneous reading while both diagrams in (29b) and (30b) indicate the anterior reading.

In terms of temporal schema (which is the combination of tense structure and tense interpretation), the $\mathrm{CC}$ past tenses schematized in (29) are different from the ones schematized in (30) in that the event time of the former type is interpreted in a direct relation to $S$, while that of the latter type is connected with $S$ via the MC time as a base time. However, both types of past tenses are tense-structurally related to each other because they both contain the A-component expressing the past time-sphere. With respect to past tenses in independent clauses and MCs, they also have the past time-sphere in their temporal structure. We can thus say that since they can all be subsumed under the concept of the past time-sphere, English past tenses represent a polysemous relation. ${ }^{16}$

16 In this respect, we should touch on Lakoff's (1970) ambiguity test, which is presented in Declerck (1995: 22) as an argument for his claim that English absolute and relative past tenses are homophonous.

(i ) John said Mary was ill, and so did Bill.

Declerck observes that (i) shows ambiguity results: the second conjunct receives the same reading of temporal relation as the first one. However, this does not necessarily prove that his claim is right. First, as Geeraerts (1993) points out, the test can yield indeterminate or vagueness results. Secondly, as Tuggy (1993) observes, ambiguity and vagueness constitute a continuum with polysemy in between. Thus the ambiguity results can apply to polysemous cases, since polysemy can be a peripheral case of ambiguity. 
In this section, I have proposed an alternative approach to the interpretation of English (past) tenses in indirect speech CCs, solving the problems with the previous analyses, and demonstrated that English past tenses are polysemous. In the next section, it will be shown that our approach can further explain related phenomena in English indirect speech from a unified point of view.

\section{Further Related Issues}

\subsection{Present Tenses in Complement Clauses}

I will first consider the case which is traditionally regarded as an exception to the sequence-of-tenses rule, namely the case where the CC tense is present while the MC tense is past. Consider (31):

(31) Bruce said that Mary is pregnant.

Note that the content of the $\mathrm{CC}$ situation is asserted by Bruce, whose viewpoint adheres to the $\mathrm{MC}$ time. The assertive form is is used to describe a situation in the present, not one in the future, vis-à-vis Bruce's viewpoint. This can be verified by the fact that sentence (31) is equivalent to sentence (32), not to sentence (33) (Yukio Hirose (personal communication)).

(32) Bruce said, "Mary is pregnant."

(33) Bruce said, "Mary will be pregnant."

This fact is accounted for by the principle in (16). Sentence (33) cannot be a paraphrase of sentence (31) because the reporter as public self cannot change the modality which is to be attributed to Bruce. Why, then, is the present tense used in (31)? The reason is that the reporter regards the $\mathrm{CC}$ situation as being true at $\mathrm{S}$ as well as at the MC time, relating it directly to his or her own viewpoint. ${ }^{17}$

The principle in (16) can also explain the contrast in (34), where the predictive form is used.

(34) a. Ryoko said that she would come with me tomorrow.

b. Ryoko said that she will come with me tomorrow.

17 This kind of tense shift seems possible only when $\mathrm{CC}$ situations are unbounded. Unlike bounded situations, unbounded situations can happen in the past and continue up to S. See Declerck and Tanaka (1996) and references cited there with respect to conditions for the use of the present tense at issue. Note, in passing, that Tanaka (1991) explains, in terms of "principle of discourse cohesion," why in some cases the use of the past tense is odd and that of the present tense is preferable in the CC even if the MC tense is past. 
It is only the $\mathrm{CC}$ tense that the reporter as public self can change on his or her own responsibility. Since the prediction associated with the predictive form is attributed to the private self, i.e. Ryoko, the reporter has to use the predictive form to satisfy (16).

\subsection{Future in the Past}

Let us now examine some apparent counterexamples to our analysis. Observe the following:

(35) a. John said that the train left at 4:50.

(Declerck (1994: 90))

b. The nurse explained that the doctor was working on Tuesday.

(Smith (1978: 59))

In (35), the $\mathrm{CC}$ verbs are both in the assertive form; nevertheless, they represent their event times as coming after the MC times.

The fact might appear contradictory to our explanation, but $(35 \mathrm{a}, \mathrm{b})$ are not counterexamples to our analysis because they are past versions of so-called futurate sentences (cf. Declerck (1994: 90)). Consider: ${ }^{18}$

(36) a. Emily leaves next Thursday.

b. Emily is leaving next Thursday. (Smith (1981a: 369))

In (36a), for instance, the verb is in the present tense while the actualization of the situation is in the future. Smith (1981a: 373) notes that the evaluation of futurate sentences holds true at $S$. This suggests that at $\mathrm{S}$ the speaker is certain of Emily's leaving next Thursday. He or she can thus assert the actuality of the situation at issue.

Based on this observation, it can be said that in (35) the private self associated with the MC time is certain of the actualization of the $\mathrm{CC}$ situation. In (35a), the situation of the train's leaving at 4:50 is predetermined by the timetable at the time of John's utterance before four-fifty. Thus John, i.e. the private self, can make an assertion about such a future-in-the-past situation. The same applies to (35b).

\subsection{Past Tenses in When-Clauses}

This subsection will show that the principle in (16) can account for

18 There are some differences in meaning and restriction between the simple present and the progressive present versions. However, explaining such differences is beyond the scope of this paper. See Smith (1981a) and Goldsmith and Woisetschlaeger (1982). 
two phenomena concerning past tenses in WCs embedded in CCs. The first concerns the case where past tenses in WCs are simple past tenses. Observe:

(37) a. Mana said that she practiced the koto in earnest for the concert when she was alone.

b. She said that they were happier when they lived in Ashford.

(Declerck (1991a: 524))

Take (37a) for example. Let us first consider practiced. The pasttense morpheme of that verb establishes the past time-sphere, and the event time is located somewhere in that time-sphere. The bounded nature of practiced the koto in earnest for the concert, together with the nature of assertion, allows (37a) to receive only the anterior reading. Let us now turn to the verb in the WC. Since the preterite was is also a finite predicate, it establishes the past time-sphere in which its event time is situated.

How, then, can we explain the reason why the WC time is construed as simultaneous with the time of Mana's practicing the koto? As is widely assumed (cf. Araki, Ono and Nakano (1977:122) and Ota (1963: 113)), I take the position that the lexical property of when itself is responsible for the relationship of simultaneity. Thus, the event time of was is construed as simultaneous with that of practiced by virtue of the property of when in the past time-sphere.

I now turn to the second phenomenon, i.e. the difference in grammaticality between the (a)- and (b)-sentences in (38) and (39).

(38) a. He said that he would help her mother when she was in trouble.

b. ${ }^{*}$ He said that he would help her mother when she would be in trouble.

(Declerck (1996: 243))

(39) a. I said I would do it when I was back home.

b. *I said I would do it when I would be back home.

(Declerck (1991a: 151))

Both would be and was in the WCs contain the past time-sphere in their tense structures. The question, then, arises as to why the predictive form (i.e. would +infinitive) in the WC is not allowed in such syntactic environments as those in (38) and (39).

To answer this question, we have to consider modal logic briefly. Let us first look at cases of present tense sentences. The verb in ifclauses and temporal clauses (TCs) cannot usually be in the predictive form when the main verb is also in that form. Observe the following: 
(40) a. *If it will rain tomorrow, the game will be canceled.

b. *John will leave when Bill will arrive.

It is often said that in these sentences, the $\mathrm{MC}$ and the subordinate clause (SC) situations make an "intensional domain," i.e. a set of propositions (cf. Lyons (1977: 170-171)), and the domain as a whole is within the scope of the modal operator associated with will. James (1986: $37-39 ; 41-43)$ convincingly notes that the main purpose of if-clauses is to represent the condition for the occurrence of the $\mathrm{MC}$, and the main purpose of TCs is to specify their temporal relation to the MC, so that such relations of the SCs to the MCs are objective. There is thus no room for subjective elements like modality to enter into the SC situations. Hence the ungrammaticality of (40).

With this in mind, let us return to (38) and (39). Sentence (38a), for example, is analyzed as follows. First, the situation of his helping her mother and that of her being in trouble make an intensional domain in the past. Secondly, was in the WC is a finite predicate and thus expresses the past time-sphere. Note, however, that the predicate at issue is neutral as to modality, since modality cannot enter into situations like those in if-clauses and TCs which constitute part of intensional domains. It may be true that the neutral form is superficially the same as the assertive form, but just because it is so does not mean that was in the WC is accompanied by assertion. Thirdly, the intensional domain represented by the whole CC is within the scope of the modal operator associated with would. From (16), it follows that the prediction represented by would is attributed to the private self, i.e. the subject of the whole sentence. Hence (38a) is grammatical.

Why, then, are sentences (38b) and (39b) ungrammatical? We can explain this by saying that they violate (16). Take (38b) for example. Since the intensional domain is associated with the modality ascribed to the private self, inserting another would into the WC would lead to the situation which, in the same intensional domain, would require another private self to which the prediction represented by that would is attributed. In fact, however, there is no such private self in (38b). The same applies to (39b). Hence, the (b) sentences in (38) and (39) are ungrammatical.

\subsection{Past Tenses in the Future}

Finally, I will analyze past tenses in the future. Observe:

(41) Mana will say that she played the koto. 
(42) In 2010, Ebenezer will say that he got tenure in 2000.

(Comrie (1986: 280))

In (41), the CC time referred to by played does not necessarily come before $\mathrm{S}$; all the temporal relation in (41) indicates is that the CC time comes before the MC time. This is justified by sentence (42) (suppose we are now in 1998). This fact might appear contradictory to our account, for we have stated that a past finite predicate establishes the past time-sphere in which its event time is located.

In order to explain this apparent contradiction, we have only to present the following generalization:

(43) In English indirect speech, the viewpoint of the public self can be shifted from $\mathrm{S}$ to the MC time when the MC time is in the future.

This generalization is compatible with (16) because in (43), the CC tense is still associated with the viewpoint of the public self. The difference between this case and the case where the MC verb is in the past tense is as follows: in the latter case, both the consciousness and viewpoint of the public self are located at $S$; in the former, the consciousness of the public self is located at $S$, but the viewpoint of the public self is shifted to a future time. Thus in (41) and (42), the CC verbs in the past tense establish the past time-sphere in relation to the MC times in the future to which the viewpoint of the public self is shifted. This point can be verified by the grammaticality of (44).

(44) Tomorrow, Mana will say that she played the koto tonight. In (44), the CC tense is past because the CC situation is located in the past relative to the viewpoint of the public self in the future; on the other hand, the consciousness of the public self is still located at $\mathrm{S}$, thus using the deictic time adverbs tonight and tomorrow.

This kind of explanation is possible because we have made a distinction between the level of tense structure and that of tense interpretation. At the tense-structure level, a predicate in the past tense (i.e. an absolute tense form) establishes a past time-sphere relative to $S$. At the tenseinterpretation level, under certain conditions the base time to which the past time-sphere is related can be shifted from $\mathrm{S}$ to a future time.

Before concluding this section, let us briefly look at (45):

(45) Mana will say that she played the koto when she was alone. To analyze this complicated sentence, we have only to use the modal logic seen in section 4.3 in addition to (16) and (43). First, it can be said from (43) that the viewpoint of the public self is shifted to the MC 
time in the future. Secondly, it follows from (16) that the preterites played and was in the embedded clause both establish the past timesphere in relation to the viewpoint of the public self. Finally, with the modal logic, the situation of Mana's playing the koto and that of her being alone constitute an intensional domain which is within the scope of the modal operator associated with the assertion ascribed to the private self, i.e. Mana. The relationship of simultaneity between the two situations is due to the lexical property of when. This is how we can interpret (45) appropriately.

\section{Conclusion}

This paper has provided a systematic and principled explanation of a variety of tense phenomena in English indirect speech CCs. First, I presented a compositional tense theory which presupposes the distinction between the level of tense structure and that of tense interpretation. At the level of tense structure, a tense form represents its original temporal value. An English finite predicate has both the A(bsolute tense) component and the R(elative tense) component: the A-component contributes to establishing a time-sphere and the R-component to locating the event time somewhere in that time-sphere. On the other hand, an English nonfinite predicate has only the R-component, representing the temporal relationship of anteriority, simultaneity or posteriority. At the level of tense interpretation, the event time can receive either a deictic or non-deictic interpretation under the influence of such elements as contexts and time adverbials; the original value of a tense form shows up by default, changes into a new value or is fixed at a certain value.

I then introduced Hirose's theory of reported speech, especially the concepts of public and private self, into the proposed tense theory in order to construct a more explanatory theory. As a result, we came to be able to explain tense phenomena concerning English indirect speech from a broader perspective. In particular, we proposed the principle shown in (16), which can not only solve some problems with, and account for exceptions to, the previous studies, but also explain various tense phenomena in indirect speech CCs. At the same time, it has been demonstrated that English past tenses are in a polysemous relation to one another because they all share the core meaning of pastness relative to the viewpoint of the public self. 


\section{REFERENCES}

Araki, Kazuo, Tsuneo Ono and Hirozo Nakano (1977) Jodoshi (Auxiliaries), Kenkyusha, Tokyo.

Binnick, Robert (1991) Time and the Verb: A Guide to Tense and Aspect, Oxford, Oxford University Press.

Comrie, Bernard (1986) "Tense in Indirect Speech," Folia Linguistica 20, 265-296.

Costa, Rachel (1972) "Sequence of Tenses in That-Clauses," CLS 8, 41-51.

Coulmas, Florian (1986) "Reported Speech: Some General Issues," Direct and Indirect Speech, ed. by Florian Coulmas, 1-28, Mouton de Gruyter, Berlin.

Dahl, Östen (1987) "Comrie's Tense," (Review Article: Tense, by Bernard Comrie, Cambridge University Press, Cambridge, 1985,) Folia Linguistica 21, 489-502.

Declerck, Renaat (1991a) A Comprehensive Descriptive Grammar of English, Kaitakusha, Tokyo.

Declerck, Renaat (1991b) Tense in English: Its Structure and Use in Discourse, Routledge, London and New York.

Declerck, Renaat (1994) "On So-called 'Tense Simplification' in English," Tense and Aspect in Discourse, ed. by Co Vet and Carl Vetters, 77-98, Mouton de Gruyter, Berlin and New York.

Declerck, Renaat (1995) "Is There a Relative Past Tense in English?" Lingua 97, 1-36.

Declerck, Renaat (1996) "Tense Choice in Adverbial When Clauses," Linguistics 34, 225-261.

Declerck, Renaat and Kazuhiko Tanaka (1996) "Constraints on Tense Choice in Reported Speech," Studia Linguistica 50, 283-301.

Enç, Mürvet (1987) "Anchoring Conditions for Tense," Linguistic Inquiry 18, 633-657.

Geeraerts, Dirk (1993) "Vagueness's Puzzles, Polysemy's Vagaries," Cognitive Linguistics 4, 223-272.

Goldsmith, John and Erich Woisetschlaeger (1982) "The Logic of the English Progressive," Linguistic Inquiry 13, 79-89.

Hirose, Yukio (1995) "Direct and Indirect Speech as Quotations of Public and Private Expression," Lingua 95, 223-238.

Hirose, Yukio (1997a) "Hito o Arawasu Kotoba to Sho-o (Words of Reference to Persons and Anaphora)," Shiji to Sho-o to Hitei (Reference, Anaphora, and Negation), ed. by Minoru Nakau, 1-89, Kenkyusha, Tokyo.

Hirose, Yukio (1997b) "Direct and Indirect Speech as Seen from Levels of Linguistic Expression: A Contrastive Analysis of Japanese and English," paper presented at the 2nd International Conference at Literary Semantics.

Hornstein, Norbert (1990) As Time Goes By: Tense and Universal Grammar, MIT Press, Cambridge, MA.

James, Francis (1986) Semantics of the English Subjunctive, University of Brit- 
ish Columbia Press, Vancouver.

Lakoff, George (1970) "A Note on Vagueness and Ambiguity," Linguistic Inquiry 1, 357-359.

Lyons, John (1977) Semantics, Cambridge University Press, Cambridge.

Mihara, Ken-ichi (1992) Jiseikaishaku to Togogensho (Interpretation of Tense and Syntactic Phenomena), Kurosio, Tokyo.

Nakau, Minoru (1994) Ninchi Imiron no Genri (Principles of Cognitive Semantics), Taishukan, Tokyo.

Ota, Akira (1963) Tense and Aspect of Present-Day American English, Kenkyusha, Tokyo.

Smith, Carlota (1978) "The Syntax and Interpretation of Temporal Expressions in English," Linguistics and Philosophy 2, 43-99.

Smith, Carlota (1981a) "The Futurate Progressive: Not Simply Future + Progressive," CLS 17, 369-382.

Smith, Carlota (1981b) "Semantic and Syntactic Constraints on Temporal Interpretation," Syntax and Semantics 14: Tense and Aspect, ed. by Philip Tedeschi and Annie Zaenen, 213-237, Academic Press, New York.

Tanaka, Kazuhiko (1991) "Eigo ni Okeru Jisei no Sho-o ni Tsuite (Sequence of Tenses in English)," Eibungaku Kenkyu (Studies in English Literature) 67, 159-172.

Tuggy, David (1993) "Ambiguity, Polysemy, and Vagueness," Cognitive Linguistics 4, 273-290.

Wada, Naoaki (1995) "On the English Pluperfect: Does It Really Represent the Pre-preterite Tense?" English Linguistics 12, 96-124.

Wada, Naoaki (1996) "Does Doc Brown Know Which Expression Takes Us Back to the Future: Be Going To or Will?" English Linguistics 13, 169198.

Wekker, Charles (1980) "Temporal Subordination in English," Linguistics in the Netherlands 1977-1979, ed. by Wim Zonneveld and Fred Weerman, 96-103, Foris, Dordrecht.

Department of Communication Studies

Ibaraki University

2-1-1 Bunkyo, Mito-shi

Ibaraki 310-8512

e-mail:naoaki@mito.ipc.ibaraki.ac.jp 